\title{
The Online Social Network and User Innovation in the Context of an Online Innovation Platform
}

\author{
Jiali Chen, School of Management Engineering, Shandong Jianzhu University, Jinan, China
}

Yikai Liang, School of Management Science and Engineering, Shandong University of Finance and Economics, Jinan, China

(iD) https://orcid.org/0000-0002-8696-4446

Jiacheng Zhang, School of Management, Shandong University, Jinan, China

Guijie Qi, School of Management, Shandong University, Jinan, China

\begin{abstract}
The wide use of social media technology boosts many online innovation platforms, providing effective communication channels for innovation spreading among online users. From the social network perspective, this paper investigates the impact of online interactive relations on user innovation by holistically examining online relations from relational and structural embeddedness, qualified by both the ego-centered and the entire network, respectively. User interaction data from LEGO Ideas are used to empirically test the effects of relational and structural characteristics of online social networks on users' idea contributions. The results for relational characteristics reveal that the number of online ties has an inverted $\mathrm{U}$-shaped relationship with user innovation, the strength of online ties positively affects user innovation, and neighbor characteristics cannot affect user innovation. For structural characteristics, both centrality and bridge location positively affect user innovation. The findings provide reasonable suggestions for both online users and innovation platforms.
\end{abstract}

\section{KEYWORDS}

LEGO Ideas, Relational Embeddedness, Social Network Analysis, Structural Embeddedness, User Innovation

\section{INTRODUCTION}

The online innovation platform refers to a virtual environment where masses of innovative users (e.g., customers, experts in certain fields,suppliers, and other interested individuals) can propose innovative ideas or solutions and interact with others to achieve collective innovation (Liang et al., 2016). In recent years, the wide use of Web 2.0 and social media technology has boosted many online innovation platforms, as represented by crowdsourcing and/or user communities (Schemmann et al., 2016; Mention et al., 2019). Some large companies have initiated their online innovation platforms to facilitate open innovation and improve their innovation performance (Palacios-Marqués, 2015). 
For example, Dell's IdeaStorm community, Starbucks's My Starbucks Idea and Salesforce.com have been pioneers in sponsoring the user innovation communities.

The continuous and high-quality innovation outcomes contributed by users are crucial for the success and the long-term operation of online innovation platforms (Palacios-Marqués, 2015; Rishika \& Ramaprasad, 2019). However, not all the firm-initiated innovation platforms are successful, and studies on how to improve innovation outcomes of online users are necessary (von Briel \& Recker, 2017). Social network theory, which emphasizes the importance of relationships among interacting individuals, deems that individuals' behaviors and outcomes (e.g., innovation) can be dramatically affected by their social environments and social structures (Granovetter, 1985). Benefiting from the development of social network analysis method and the accessibility of online users' interaction data, some scholars have explored the impact of online relationships on users' innovation behaviors from the network perspective, aiming to find some theoretical evidence on how to improve users' innovation outcomes.

Among the studies in this area, some scholars view online interactive relations as one of the most critical aspects of social capital, focusing on users' online social ties and how they benefit user innovation (Yang \& Li, 2016; Guo et al., 2017). The online users can interact with others by friending or following each other and by voting or commenting on others' proposals, through which the online ties between users are developed (Arnaboldi et al., 2017). Online ties can benefit users with information and knowledge acquired from connected others and enable social learning between users (Riedl \& Seidel, 2018). These online ties play an important role in inspiring users with new ideas. Moreover, the online interactions for all users form the network. Some scholars investigate the structure of the online social network and the diffusion of innovation in the network (Karsai et al., 2014; Arnaboldi et al., 2017). Based on innovation diffusion theory (Rogers, 2003) and the complex social network analysis method, they find evidence of the social influence among online network members; that is, one member's behavior is influenced by the connected others, and the network structure affects the diffusion of information and innovation in the network (Centola, 2010). To summarize the points of prior studies, online users' social networks would bring both resource benefits and social influence for network members, which would help online users promote their innovation outcomes. However, few studies consider the two aspects of the online social network together when they explore the networks' effects on user innovation.

The practical and theoretical issues mentioned above motivated us to holistically examine the impact of online social networks on user innovation. To address this, we begin with social embeddedness to produce our dimensions of social network analysis. Sociologists argue that individuals and their behaviors are embedded in a society composed of a variety of social relations (Granovetter, 1985; Granovetter, 1992). Generally, there are two kinds of embeddedness - relational embeddedness and structural embeddedness, which provide the two dimensions when we explore the effects of online users' social networks. Relational embeddedness stresses the nature of social relations and focuses on the role of social relations as a mechanism for gaining fine-grained benefits. Goyal (2012) views this as the local network effect, which examines how one user's social relations influence his/her behavior and outcome through direct ties with other users. Structural embeddedness goes beyond direct ties and emphasizes the benefits of the structural position individuals occupy in the social network. Goyal (2012) identifies this as the global network effect, which examines how entire network relations (i.e., direct \& indirect ties) influence user innovation through the network structure.

As Granovetter (1992, p. 33) has noted "that economic action and outcomes, like all social action and outcomes, are affected by actors' dyadic (pairwise) relations and by the structure of the overall network of relations", both relational embeddedness and structural embeddedness should be considered when studying the effects of the social network. Hence, this paper investigates online users' social network from both the relational dimension (i.e., the characteristics of the social ties) and the structural dimension (i.e., the characteristics of the network structure), by examining the "ego-centered" network and the entire network respectively. Specifically, we use the method of social 
network analysis to quantify the relational characteristics (i.e., the number of ties, the strength of ties, the innovation characteristics of neighbors) and structural characteristics (i.e., centrality, bridge location), and consequently explore their effects on user innovation (i.e., numbers of ideas, quality of ideas) through regressions. This study offers complementary insights to previous studies by examining the impact of online interactive relations from a holistic perspective.

The rest of the paper is structured as follows. The next section describes the relevant literature, followed by the development of the hypotheses. We propose hypotheses regarding the effects of the relational and structural characteristics of online user social networks on user innovation. The Empirical Methodology section presents the data and variables for empirical analysis. We select one online innovation platform - LEGO Ideas — as the research context and build its social network by crawling the users' online interaction data. Then, we measure the relational and structural characteristics by calculating some network indicators as well as the measurements for other variables. The Empirical Results section details the results of the empirical analysis and robustness checks. Finally, this paper summarizes the main conclusions and presents its contributions and implications.

\section{THE RELATED LITERATURE FROM THE SOCIAL NETWORK PERSPECTIVE}

Rogers (2003) illustrates that innovation is diffused through a certain social network. The social media technology and its widespread availability facilitate the user interactions in online innovation communities, which provides effective communication channels for the innovation spreading to other users, enabling collaboration and knowledge sharing. Stanko (2016) adapts Roger's theorization to address the context of the online innovation community by involving new considerations - community users' desire to learn, and the fluid, interactive, publicly visible nature of online communities. The community users can adopt/remix other's ideas to develop new concepts, which facilities the diffusion of innovation among the worldwide community users. Di Gangi and Wasko (2009) also adapt the innovation diffusion theory to explore the factors influencing the organizational adoption of online user innovations.

Under the condition of innovation diffusion through the online social network, social capital theory (Coleman, 1988; Tsai \& Ghoshal, 1998) provides the theoretical foundation for understanding the relationship between social networks and individual innovation. Lin (2002) defines social capital as the valuable resources embedded in social networks, which are owned by others who have direct or indirect relations with the focal individual. Individuals' social capital can help individuals achieve certain goals (e.g., innovation) by enabling them to access useful resources (e.g., knowledge and information) from connected others (Chiu et al., 2006). Drawing on Granovetter's discussion of structural and relational embeddedness (Granovetter, 1992), Nahapiet and Ghoshal (1998) clarified the structural and relational dimensions of social capital and how they facilitate the creation and exchange of knowledge. Thus, we review the literature on the benefits of social networks on innovation from both the relational embeddedness mechanism and the structural embeddedness mechanism.

\subsection{Relational Embeddedness and User Innovation}

Relational embeddedness focuses on the kind of personal relationships people have developed through a history of interactions (Nahapiet \& Ghoshal, 1998). The key facets of the relations between individuals include trust and trustworthiness, identity and identification, and feelings of closeness or interpersonal solidarity. Some studies have proved that individuals who have more online social ties contribute more knowledge or innovation outcomes (Chan et al., 2015; Yang \& Li, 2016). As one of the most important aspects of social capital, social relations developed by online interactions (e.g., "followers", "friends", "commentators") can help users cultivate more knowledge and information from others and thus generate new creative ideas (Chiu et al., 2006).

Meanwhile, some studies explore social relations from the strength perspective. Granovetter (1973) explains the strength of ties, reflecting the degree of intensity, frequency of intimacy (trustworthiness), 
reciprocity, and acknowledged obligations. He distinguishes strong ties and weak ties according to their strength and focuses on the advantages of weak ties. Weak ties tend to provide people with access to more nonredundant information and resources. Under the context of online communities, some scholars believe that strong ties also have advantages. The stronger the relationships between two people are, the stronger their trust is (Bapna et al., 2017), and the more likely they are to share and exchange high-quality resources and tacit knowledge (Nonaka, 1994) with each other (Reagans \& McEvily, 2003). Yang and Li (2016) measure the strength of ties by the norm of reciprocity in the online innovation community in China (MIUI) and find that strength mediates the effect of the number of ties on the knowledge outcomes.

Moreover, a few scholars develop an exploration of the multiple dimensions of online relations. Chan et al. (2015) consider individuals' interactive relations in one crowdsourcing community from three aspects - direction, size, and tie strength (i.e., the frequency of interactions) - and find positive effects of interactive relations on individuals' idea generation. Additionally, Rishika and Ramaprasad (2019) examine the directions of the online ties (i.e., one-way ties or reciprocated ties), and find that reciprocated ties (i.e., two-way ties) exert a greater influence on users' contribution behavior than one-way ties, while tie strength among network ties amplify the effect.

\subsection{Structural Embeddedness and User Innovation}

Structural embeddedness focuses on the impersonal configuration or structure of social relations, referring to the social network's structural properties and the location of individuals in the network (e.g., density, connectivity, and hierarchy) (Nahapiet \& Ghoshal, 1998). The network structure affects the innovation diffusion in the network through the informational mechanisms (i.e., awareness and learning) and persuasive mechanisms (i.e., normative pressure and network externalities) (Muller $\&$ Peres, 2019). The critical structural location determines with whom the individual can interact directly and indirectly, which would provide advantages for the individuals to control information and resources.

Some scholars proxy the structural embeddedness by centrality. Wasko and Faraj (2005) study users' knowledge contribution on one online knowledge community and find that people contribute their knowledge when they are structurally embedded in the network. Grewal et al. (2006) focus on the community-based open source software (OSS) development, and find that network embeddedness has strong and significant effects on both technical and commercial success of open source projects. Through artificially structured online communities, Centola (2010) finds that individual behavior spreads farther and faster across clustered-lattice networks than across corresponding random networks.

Another critical structural position in networks, in addition to the structural embeddedness indicator, is the bridge location or brokerage. Burt (2004) argues that individuals located in a structural hole position, as a bridge connecting the various parties, can exchange resources between different groups. The location of a structural hole helps individuals obtain more nonredundant and heterogeneous information. Applying social network analysis, Toral et al. (2010) identify three different groups of users by investigating the structure of the online social network for OSS projects, and identify the brokerage as the key role to be performed by the core of the community. These brokers behave as the intermediary between expert software developers and peripheral users, helping OSS projects engage in discourse and colearning experiences with their user communities. Stephen et al. (2016) focus on the interconnectivity between the individual's online neighbors and obtain a similar finding. They find that low interconnectivity tends to bring more nonredundant information to the focal innovator, which helps promote the ideas' innovativeness of the focal innovator.

In summary, social relations and structural positions are two noteworthy aspects in the study of online social networks and their implications, while both the relational and structural aspects of social networks contain multiple dimensions (Scott, 2012). Few scholars have explored the effects of multidimensional social networks on online user innovation. Multidimensional properties of online 


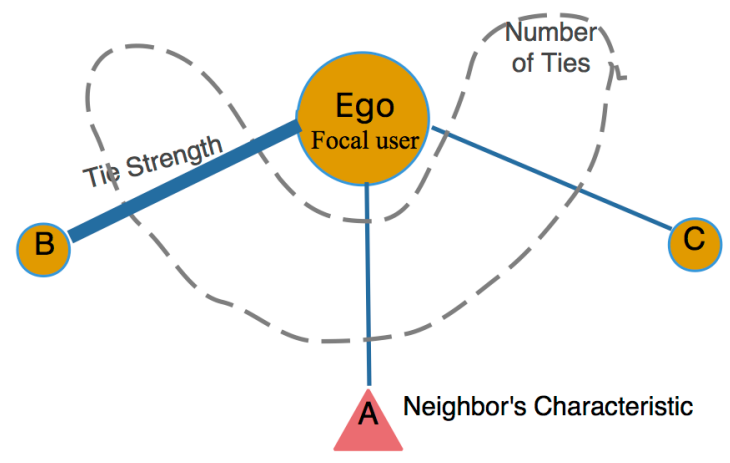

social networks, that is, characteristics taking both the relational and structural dimensions into account, and their effect on user innovation need further exploration.

\section{HYPOTHESES DEVELOPMENT}

Following previous studies from the social network perspective, this study examines the impact of the online user network on user innovation from both relational and structural dimensions.

\subsection{The Relational Dimension}

Early sociologists and social anthropologists often use the "ego-centered" network to examine the social features of personal relationships (e.g., reciprocity, intensity, durability) and their implications (Bott, 1957; Wellman, 1979). The "ego-centered" network consists of a focal actor, termed ego, a set of alters who have ties to the ego, and measurements on the ties among these alters (Wasserman \& Faust, 1994). The "ego-centered" network is one suitable tool for examining the relationships the focal user has developed through online interactions as well as their impacts on information diffusion (Arnaboldi et al., 2017). Thus, we build the ego-centered network for each user to investigate the relational characteristics of the online user network, as shown in Figure 1.

In the ego-centered network, the number and strength of ties are two characteristics for measuring relational embeddedness commonly used by previous scholars. Moreover, according to social influence theory, individuals will be influenced by others' characteristics to change their attitudes, tending to converge their behaviors (Cialdini \& Goldstein, 2004). Hence, the neighbors' characteristics are also an essential factor to be considered. Thus, we examine the relational dimension of online user social networks based on the number of ties, the strength of ties, and the neighbors' innovation characteristics and consequently propose our hypotheses.

\subsubsection{The Number of Ties}

According to social capital theory, the number of ties is often closely related to the resources that individuals can access from their social network (Lin, 2002). Previous scholars studying social relations and innovation hold that the more social ties there are, the more information and innovation knowledge individuals can obtain from others (Wasko \& Faraj, 2005; Yang \& Li, 2016). Consequently, individuals can generate innovative ideas by rearranging or combining information and knowledge in new ways (Kohn et al., 2011). However, other scholars argue that when the number of ties is overloaded, the benefits of accessing information can be reduced, as can innovation performance (McFadyen \& Cannella Jr., 2004). Based on the pros and cons of the number of ties, a few scholars have proposed 
and confirmed that the number of ties (e.g., the working ties) and innovation performance show a curvilinear relationship (McFadyen \& Cannella Jr., 2004; Zhou et al., 2009).

We argue that this pattern still exists in online networks. On online innovation platforms, maintaining relationships with others requires time, energy, and attention, such as taking the time to respond to others' innovation activities (e.g., viewing/supporting/commenting on others' new ideas). The higher the number of online interactive relationships that one user must maintain, the less the effort and time that the user can devote to innovation. Before the number of online ties reaches a certain threshold, more online interactive relationships will bring users useful information and knowledge to cultivate more and better innovation outcomes because insufficient information and knowledge will limit inspiration. Nevertheless, when the number of online ties becomes large enough and is beyond the optimized level, individuals are likely to experience information overload and redundancy. Moreover, when the number of online ties surpasses the threshold, the high cost of relationship maintenance and reciprocity obligations will exceed the innovation benefits. Thus, an increasing number of ties eventually leads to less new knowledge creation. From the above arguments and evidence, we propose the following hypotheses:

H1a. The number of ties that users maintain has a quadratic (inverted U-shaped) relationship with the number of users' ideas.

H1b. The number of ties that users maintain has a quadratic (inverted U-shaped) relationship with the quality of users' ideas.

\subsubsection{The Strength of Ties}

The strength of ties refers to the frequency and depth of interaction between connected individuals, reflecting the intensity of the relationships and the trustworthiness between individuals (Granovetter, 1973). In online virtual environments, frequent user interactions lead to trustworthiness between anonymous users, which plays a vital role in maintaining online relations (Ellison et al., 2014). Thus, the strength of ties can be measured by the frequency of various interactive actions. In particular, user interactions on online innovation platforms are generally designed to occur around user innovation; for example, one user can interact with others by voting/supporting/commenting on others' ideas. User interactions on innovation platforms also refer to the flow of innovation information and knowledge between users (Kane et al., 2014). The stronger the strength of the tie between users, the more useful information and knowledge is transferred between them, which further helps improve user innovation (Reagans \& McEvily, 2003).

Additionally, useful innovation knowledge tends to be sophisticated tacit knowledge, which is difficult to externalize and transfer (Nonaka, 1994). Some studies have illustrated that the high strength of a relationship helps exchange complex information and tacit knowledge (Levin \& Cross, 2004). Repeated interactions between individuals encourage them to form a shared language and consistent coding standards during communication, facilitating the exchange of complex information and the transmission of tacit knowledge. Thus, the stronger the ties between online users, the more likely the users are to exchange, understand, and absorb innovation knowledge wholly and smoothly, which would be helpful for users produce more and better innovation outcomes. Thus, we propose the following hypotheses:

H2a. The strength of ties is positively related to the number of users' ideas. $\mathrm{H} 2 \mathrm{~b}$. The strength of ties is positively related to the quality of users' ideas.

\subsubsection{The Innovation Characteristics of Neighbors}

The studies focusing on the process of innovation diffusion have found evidence of social influence among anonymous online users (Centola, 2010). Karsai et al. (2014) analyze a dataset recording 
users' adoption behaviors of the world's largest Voice over Internet Protocol service (i.e., Skype) over time and find that the more the online neighbors who use the Skype app, the more likely that the focal user also chooses to use Skype. The probability of adoption behavior via social influence is linearly proportional to the fraction of adopting neighbors. Furthermore, the social influence exists in the connections of both the reciprocal ties and the one-way ties (Panzarasa et al., 2010; Goes et al., 2014). Thus, the online neighbors in the innovation platforms would also have peer influence on the focal user. The more ideas the online neighbors propose, the more likely that the focal user also intends to propose more ideas. Thus, we propose the following hypotheses:

H3a. The number of ideas online neighbors proposed is positively related to the number of focal users' ideas.

In the presence of social influence, the users who propose popular ideas (i.e., the leaders) would exert strong peer pressure on their neighbors, even shaping the way that others would act (Huffaker, 2010). Generally, online innovation platforms would rank users' ideas through peer evaluation. For example, Dell IdeaStorm invites users to vote on ideas (e.g., promote or demote the ideas) and obtain the total points of ideas. The ideas with top points would be displayed on the website homepage. Meanwhile, LEGO Ideas allows users to give support to the ideas they like. The number of points or support of one idea reflects the popularity and quality. The social relations with users who proposed popular ideas would motivate the focal user to make efforts to improve the ideas' quality and make it popular.

Moreover, a user who has posted popular and/or high-quality ideas holds a higher innovation level. Such users tend to have more and richer useful information and master a vast amount of both explicit and tacit knowledge that can produce better innovation outcomes. Akcigit et al. (2018) have reported that interactions with high-level innovators in patent cooperation could increase subsequent patent quality, but interactions with low-level innovators accomplish the opposite. Hence, ties with highlevel innovators can help users obtain more valuable and useful innovation knowledge and resources, which are essential inputs for helping users to break through their original pattern of thinking and generate more creative actions. Above all, we propose the following hypotheses:

H3b. The innovation level of neighbors is positively related to the quality of the focal users' ideas.

Figure 2 illustrates the research model investigating the effect of relational characteristics of the user social network.

\subsection{The Structural Dimension}

We take the entire network, composed of all users and their ties with others, to investigate the online user network's structural characteristics. This study examines the structural characteristics in terms of centrality and bridge location, which have been tested as two important structural positions by previous scholars (Burt, 2004; Wasko \& Faraj, 2005).

\subsubsection{Centrality}

The centrality of an individual represents that individual's prominence in the network, identifying individuals believed to have a more considerable influence and status in the network (Wasserman $\&$ Faust, 1994). The person in the central position tends to have more contacts with others or gains contact with others faster. Some studies have confirmed that high network centrality is conducive to improving innovation performance in the enterprise network (Lin et al., 2009). The centrally located enterprise has the advantage of obtaining more useful information and resources from other directed and undirected connected enterprises. 
Figure 2. Relational Characteristics of the User Social Network and User Innovation

Relational Characteristics

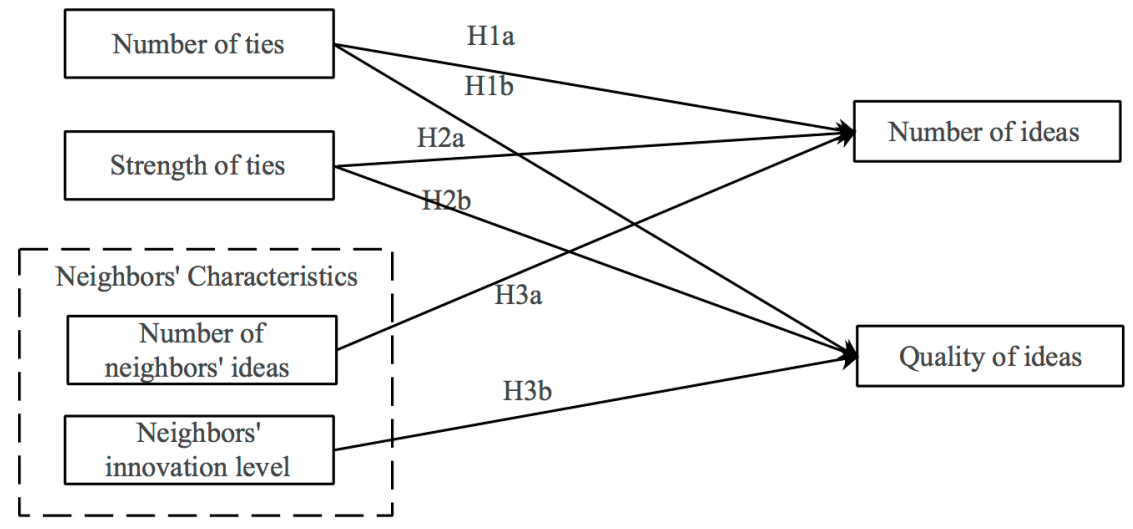

On the online innovation platform, network centrality can also provide users with resource advantages, which are the advantages of sharing and exchanging innovation knowledge with others. Because it provides the most attention from others in the network, the central location becomes the main channel for accumulating useful information and knowledge (Freeman, 1978). Centrality determines the ability to control resources, information, and knowledge. Additionally, high centrality can provide users with more chances to acquire resources from others. Given that the user in the center of the network often enjoys a higher status and reputation, people are more likely to share innovative knowledge with them due to that good reputation. Because individuals with a good reputation are more inclined to choose to cooperate and reciprocate with others with a low risk of betrayal (Pollock $\&$ Dugatkin, 1992). Thus, high centrality would also provide users with more chances to exchange innovative knowledge with others. Considering the above arguments and evidence, we propose the following hypothesis:

H4a. Centrality in the network is positively related to the number of users' ideas.

H4b. Centrality in the network is positively related to the quality of users' ideas.

\subsubsection{Bridge Location}

A bridge is a connection between two groups, which is also a powerful strategic position in the network. Individuals at the bridge location undertake a critical task of acquiring resources embedded in the two groups as much as possible and transferring heterogeneous information from one group to another. Based on social capital theory, Burt (1992) advances the structural hole theory, discussing the bridge location in depth using some social network analysis methods. In one network, a structural hole is a gap between nonredundant contacts through which two nonredundant actors can be "connected". Actors in a network who occupy more structural holes will be able to access novel information from remote parts of the network and exploit that information to their advantage.

Regarding online user social networks, we argue that the bridge location (i.e., access to structural holes) is still a powerful strategic position. Dunbar et al. (2015) study several popular online social networking sites (i.e., Facebook, Twitter) and find that online networks exhibit similar structural characteristics to traditional offline social networks. Although the Internet has dramatically increased the transparency of information and its accessibility, it is worth noting that the amount of Internet information is quite large and continues to increase at an extremely rapid pace. The time and energy each person can spend on acquiring and processing information are limited. 
Figure 3. Structural Characteristics of the User Social Network and User Innovation

Structural Characteristics

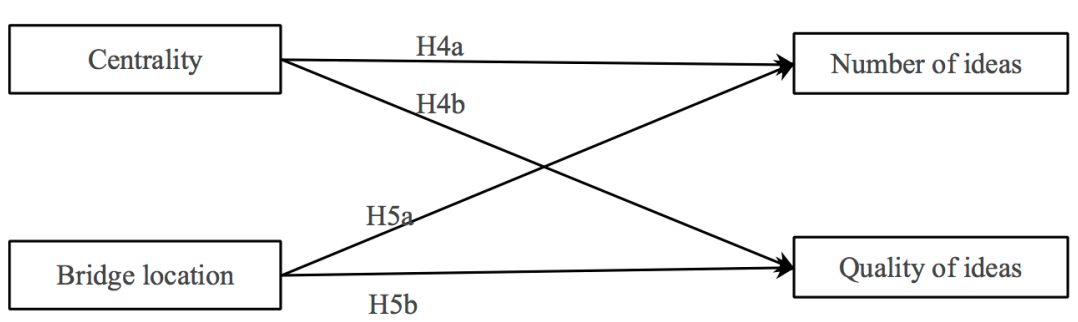

We take the LEGO Ideas platform as an example; there are more than one million registered users and tens of thousands of active users who have posted ideas on the platform. It is unrealistic for one user to establish relationships and exchange information with all the other users. Therefore, the bridge location is still an advantageous strategic position to facilitate online users quickly accessing high-value information (e.g., nonredundant innovation knowledge) from heterogeneous groups with limited time and effort. Thus, we propose the following hypothesis:

H5a. The bridge location, i.e., access to structural holes, is positively related to the number of users' ideas.

H5b. The bridge location, i.e., access to structural holes, is positively related to the quality of users' ideas.

Figure 3 indicates the research model investigating the effect of structural characteristics of the user social network.

\section{EMPIRICAL METHODOLOGY}

\subsection{LEGO Ideas Platform and Data}

We use the LEGO Ideas platform (URL: ideas.lego.com) as the research context to investigate an online user social network. Formally initiated in April 2014, LEGO Ideas is one of the most successful online innovation platforms, aiming to collect innovative ideas from global LEGO fans. Registered users can submit their ideas for original block models and then collect support to select the best ones for commercialization. By the end of 2020, the platform had attracted over 1.5 million registered users, contributing over tens of thousands original block models. Moreover, many block designs have been commercialized and are very popular with customers, such as WALL $\bullet E$ and LEGO Minecraft.

Because there are millions of users on the LEGO Idea platform, it is unrealistic and unnecessary to include all users (active users and inactive users) in the scope of the study. Given our research purpose, this paper focuses on active users who submitted ideas in 2017 as the research sample (2043 users) and uses Python crawler programs to collect their data. The data include two categories: relational data and attribute data. Relational data refers to the information about who interacts, associates, or connects with whom. This study focuses on the "follow-up" ties of the sample users and their interactions with others (i.e., supporting and commenting on others' ideas). Attribute data refers to the information about an individual's attitudes, characteristics, and behaviors, which are deemed to be one's attributes and are usually used for quantitative analysis, e.g., users' platform age, users' platform points and badge, the number of ideas submitted, the number of supporting statements for their ideas. 


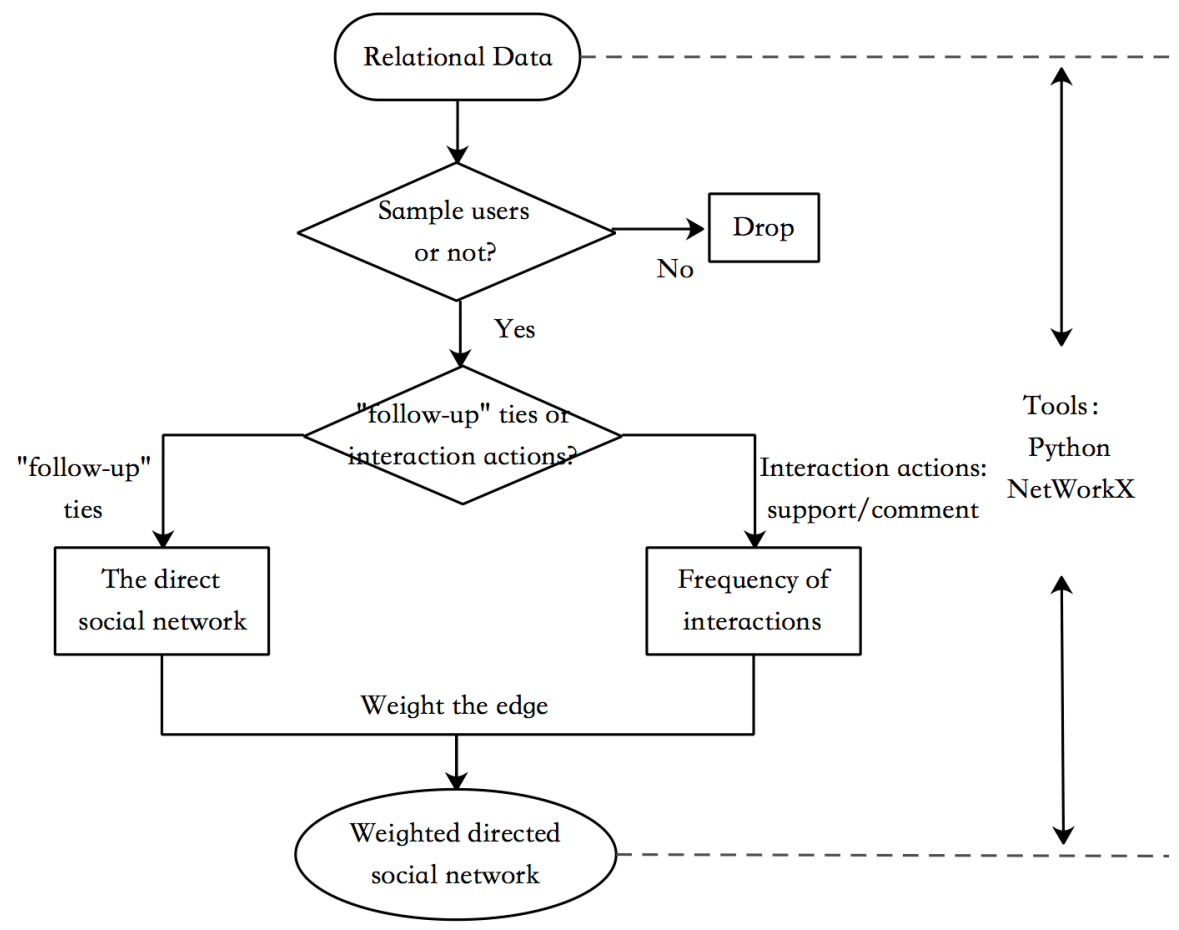

\subsection{The User Social Network on the LEGO Ideas Platform}

Based on the relational data, this paper constructs a user social network using the Python NetworkX package. Figure 4 shows the procedures of network construction. The user social network is a weighted directed network in which the nodes refer to the platform users, the directed edges refer to the "follow-up" ties from one to another, and the weights of edges refer to the frequency of user interactions (i.e., the actions of supporting and commenting).

The user social network is visualized in Figure 5, in which the nodes' size refers to the node in-degree, that is, the number of users' followers. This network exhibits a core-periphery structure with a large core, representing that most users are concentrated in and around the core location. The core users are closely connected and have more followers. The others, who have less or even no followers, are scattered around.

Table 1 briefly reports more characteristics of the user social network. The network includes 2043 nodes and 17,094 directed edges, with a network density of 0.0041 . Approximately 93.73\% of users have connections with others, with an average of approximately 17 one-way ties and 2 pairs of reciprocal ties (i.e., the two users follow each other) for each user. Moreover, the clustering coefficient, i.e., the proportion of all two-paths in the network that are closed, is 0.049 , which reflects the egocentric density. Compared with the randomly generated networks ${ }^{1}$, the user social network shows a significantly larger clustering feature. Furthermore, the average path of the user social network, i.e., the length of the shortest distance between two users that are reachable, is approximately 3 . It means that, on average, it takes only two intermediaries for any two users to pass information to each other. The diameter, i.e., the longest path between two reachable users, is 8. Overall, the user social network of LEGO Ideas shows a small-world characteristic (Watts \& Strogatz, 1998). 


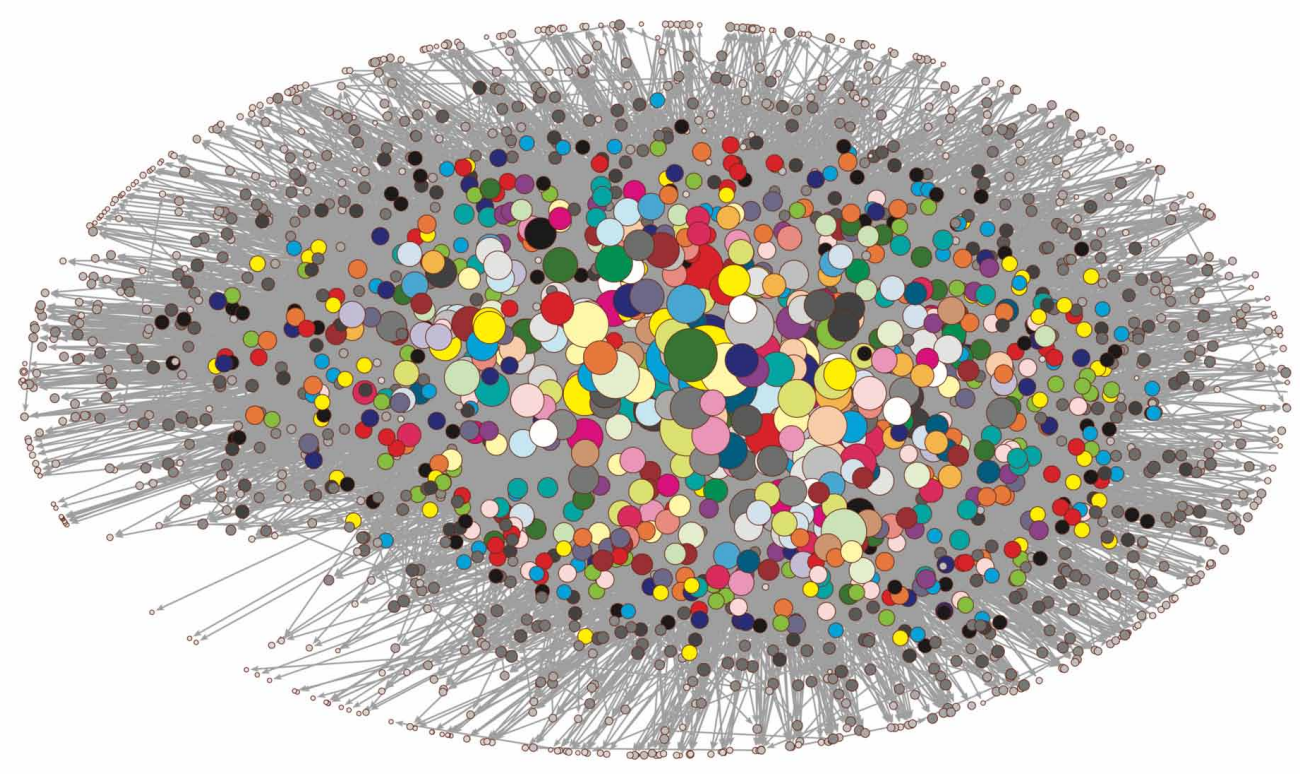

\subsection{Variables and Measurements}

\subsubsection{Relational Characteristics}

\subsubsection{The Number of Ties}

Specifically, we use the ego-centered network to define and qualify the characteristics of online relations. The work of Rishika and Ramaprasad (2019) \& Goes et al. (2014) have proven the social influence of online one-way ties. Additionally, we consider the user relations by the directed ties between users, i.e., both the inward ties and outward ties. The inward ties are the ties received by the ego, and the outward ties are the ties sent by the ego. For each user, we qualify the number of ties by the ego's node degree in the ego-centered network, i.e., the sum of node in-degree and out-degree. The in-degree refers to the number of users who follow the focal user, while the out-degree refers to the number of uses that the focal user follows.

\subsubsection{The Strength of Ties}

We measure the strength of ties by the frequency of user interactions, i.e., supporting and commenting actions of users on the LEGO Ideas platform. We calculate the average number of user interactions for the ego to proxy the ties' strength, as shown in Equation (1). $n$ represents the number of neighbors

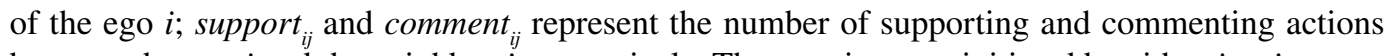
between the ego $i$ and the neighbor $j$, respectively. These actions are initiated by either $i$ or $j$.

Table 1. The Characteristics of the User Social Network

\begin{tabular}{|l|l|l|l|l|l|l|l|l|}
\hline $\begin{array}{l}\text { No. of } \\
\text { nodes }\end{array}$ & $\begin{array}{l}\text { No. of } \\
\text { isolated } \\
\text { nodes }\end{array}$ & $\begin{array}{l}\text { No. of } \\
\text { edges }\end{array}$ & $\begin{array}{l}\text { Average } \\
\text { degree }\end{array}$ & $\begin{array}{l}\text { Average } \\
\text { reciprocal edges }(/ \\
\text { pairs })\end{array}$ & $\begin{array}{l}\text { Network } \\
\text { density }\end{array}$ & $\begin{array}{l}\text { Clustering } \\
\text { coefficient }\end{array}$ & $\begin{array}{l}\text { Average } \\
\text { path }\end{array}$ & Diameter \\
\hline 2043 & 128 & 17,094 & 16.73 & 2.13 & 0.0041 & 0.049 & 2.97 & 8 \\
\hline
\end{tabular}




$$
\text { strength }_{i}=\left\{\frac{\sum_{j}\left(\sup \text { port }_{i j}+\text { comment }_{i j}\right)}{\frac{n}{0}} \quad n=0 \quad j \in[1, n], n>0\right.
$$

\subsubsection{The Innovation Characteristics of Neighbors}

According to the hypotheses proposed in the above section, we consider two kinds of neighbors' characteristics: the number of ideas online neighbors propose and the innovation level of these neighbors. First, we calculate the average number of neighbors' ideas, as shown in Equation (2). Second, according to users' history of innovation in LEGO Ideas, we identify the high-level innovators and common innovators. The LEGO Ideas platform would award the "1K Badge" to users with any idea receiving over 1,000 supporting statements, who will be deemed excellent innovators by the platform and users. Hence, we categorize users with a "1K Badge" as high-level users and those without the badge as common users. Thus, we measure the neighbors' innovation level by the proportion of high-level neighbors to all neighbors of the focal user, as shown in Equation (3). In practice, we use the Python NetworkX package to automatically count the number of high-level neighbors and calculate its share.

$$
\begin{array}{ll}
\text { neighbors }_{\text {ideas }_{i}}=\left\{\frac{\sum_{j} \text { ideas }_{j}}{\frac{n}{0}} \quad n=0\right. & j \in[1, n], n>0 \\
\text { neighbors_level }_{i}=\left\{\frac{\sum_{j} \text { highlevel }_{j}}{\frac{n}{0}}\right. & n=0 \quad j \in[1, n], n>0
\end{array}
$$

In Equation (2) and (3), $n$ represents the total number of neighbors of the ego $i$; ideas denotes the ideas' number of the neighbor $j$; and highlevel denotes whether the neighbor $j$ is a high-level innovator or not. highlevel $=1$ if the user is a high-level innovator, highlevel $=0$ if the user is not.

\subsubsection{Structural Characteristics}

\subsubsection{Centrality}

We qualify the structural characteristics through the entire network. For the directed network, an individual's centrality can be measured by the notion of prestige (Wasserman \& Faust, 1994). A prestigious actor refers to the user everyone rushes to follow, focusing solely on the user actor as a recipient. Thus, the centrality can be simply qualified by node in-degree centrality. We use standardized node in-degree centrality to measure the variable centrality. This standardized index ranges from 0 to 1 and can be compared across networks of different sizes.

Furthermore, we select two other commonly used indicators, eigenvector centrality (Bonacich, 1987) and closeness centrality (Freeman, 1978), as alternative indicators of centrality for robustness checks. Our measure for centrality has been used by Grewal et al. (2006), who also adopt several indicators as a centrality-based measure of structural embeddedness. Eigenvector centrality captures the idea that the more central the neighbors of one user are, the more central that the user itself is, which can be expressed in terms of eigenvector solutions of appropriately defined linear systems of equations. Closeness centrality illustrates how close one user is to the other users in the network, which is measured as a function of geodesic distances of the focal user from all others. In the directed network, the two centrality indicators can be calculated from two directions - inward and outward. 
Regarding the user actor as a recipient, analogous to prestige, both the eigenvector centrality and closeness centrality are calculated and standardized solely by the inward direction. All these indicators are computed by Python NetworkX.

\subsubsection{Bridge Location}

The degree close to the bridge location can be qualified by the access to the structural hole. According to the structural hole theory of Burt (1992), the network constraint is used to proxy the structural hole. "The constraint on a manager is high if the manager's discussion partners talked a lot to one another directly (dense network) or if they shared information indirectly via a central contact (hierarchical network).... I measure the network constraint on each manager with respect to the immediate network of discussion partners, composed of anyone the manager cited as a discussion partner and anyone who cited the manager. (Burt, 2004, p. 362)". In short, more constrained networks spanned fewer structural holes. Thus, in the first place, we compute the network constraint $C_{i}$ for user $i$, by the social network analysis software Pajek, according to the calculation method of Burt (1992). Regarding that the network constraint is negatively related to the structure hole, then we construct the variable bridge ${ }_{i}$ $=1-C_{i}$ to measure the degree of bridge position.

\subsubsection{Dependent Variables}

In this paper, we evaluate user innovation using two variables: the number of ideas and the quality of ideas. The number of ideas refers to the total number of ideas released by sample users in 2017. The quality of ideas refers to the average number of supporting statements those users' ideas obtained in 2017, which is a commonly used measure of idea quality in previous studies (e.g., Jabr et al., 2014).

\subsubsection{Control Variables}

The individual characteristics of users are important factors affecting their innovation outcomes. Therefore, this study selects the following user characteristics as control variables. To measure users' innovation experience and their innovation level, we collect the number of past ideas posted by users and identify whether they are high-level users (Hwang et al., 2019). Additionally, we construct social tendency to assess whether a user tends to actively interact or share their knowledge with others (Černe et al., 2014). In the LEGO Ideas platform, we retrieve the number of Socializer Badges owned by a user to gauge their social tendency. Considering the users' experience with platform usage, we also control for the user's platform age (Li et al., 2016).

Table 2 provides the descriptions of all variables, and Table 3 provides the summary statistics.

\subsection{Empirical Models}

The empirical models are built to examine the effects of the user social network's relational and structural characteristics, respectively. Model M1 investigates the impact of relational characteristics on user innovation, i.e., the effects of direct relations (local effect). We consider user innovation outcomes from both quantity and quality perspectives. Thus, the dependent variable is the number of users' ideas (ideas_quantity) for M1 a, and the quality of users' ideas (ideas_quality) for M1b. The main explanatory variables are three relational characteristic variables: the number of ties (ties), the strength of ties (strength), and the innovation characteristics of neighbors (neighbors). For M1a, the innovation characteristic of neighbors refers to the number of ideas the neighbors propose (neighbors_ ideas). For M1b, the innovation characteristic of neighbors refers to the innovation level of neighbors (neighbors_level). Additionally, $X$ in the two equations refers to the control variables, i.e., the users' characteristics. $\varepsilon_{i}$ are the error terms. 
Table 2. Description of Variables

\begin{tabular}{|c|c|c|}
\hline Variable & Notation & Description \\
\hline \multicolumn{3}{|l|}{ Dependent variables } \\
\hline The number of ideas & $\begin{array}{l}\text { ideas__ }_{-} \\
\text {quantity }\end{array}$ & The total number of ideas released by users in 2017 \\
\hline The quality of ideas & ideas_quality & $\begin{array}{l}\text { The average number of supporting statements users' ideas received in } \\
2017\end{array}$ \\
\hline \multicolumn{3}{|c|}{ Relational characteristics } \\
\hline The number of ties & ties & The node degree (i.e., the sum of in-degree and out-degree) \\
\hline The strength of ties & strength & The average number of user interactions between connected users \\
\hline $\begin{array}{l}\text { Number of neighbors' } \\
\text { ideas level }\end{array}$ & $\begin{array}{l}\text { neighbors_ } \\
\text { ideas }\end{array}$ & The average number of ideas online neighbors propose \\
\hline $\begin{array}{l}\text { Neighbors' innovation } \\
\text { level }\end{array}$ & $\begin{array}{l}\text { neighbors_ } \\
\text { level }\end{array}$ & The proportion of neighbors with a high innovation level to all neighbors \\
\hline \multicolumn{3}{|c|}{ Structural characteristics } \\
\hline Centrality & central & In-degree centrality, eigenvector centrality, and closeness centrality \\
\hline Bridge location & bridge & $1-C_{i}$ (the network constraint of the structural hole) \\
\hline \multicolumn{3}{|l|}{ Control variables } \\
\hline Innovation experience & pastideas & The number of ideas posted by users in the past \\
\hline Innovation level & highlevel & $\begin{array}{l}\text { highlevel }=1 \text { if the user is a high-level innovator; } \\
\text { highlevel }=0 \text { if the user is not a high-level innovator. }\end{array}$ \\
\hline Social tendency & socializer & Number of Socializer Badges a user received \\
\hline Platform age & user_age & The user's platform age (month) \\
\hline
\end{tabular}

Table 3. Summary Statistics

\begin{tabular}{|l|l|l|l|l|l|}
\hline Variable & No. of observations & Mean & Standard Deviation & Minimum & Maximum \\
\hline ideas_quantity & 2,043 & 2.106 & 3.304 & 1 & 60 \\
\hline ideas_quality & 2,043 & 215.718 & 742.602 & 1 & 10,000 \\
\hline ties & 2,043 & 16.734 & 53.723 & 0 & 1,086 \\
\hline strength & 2,043 & 2.327 & 1.351 & 0 & 10.571 \\
\hline neighbors_ideas & 2,043 & 6.949 & 7.388 & 0 & 77 \\
\hline neighbors_level & 2,043 & 0.092 & 0.163 & 0 & 1 \\
\hline central_indegree & 2,043 & 0.004 & 0.006 & 0 & 0.074 \\
\hline central_eigenvector & 2,043 & 0.014 & 0.018 & 0 & 0.132 \\
\hline central_close & 2,043 & 0.090 & 0.026 & 0 & 0.139 \\
\hline bridge & 2,043 & 0.629 & 0.344 & 0 & 0.989 \\
\hline pastideas & 2,043 & 1.571 & 6.138 & 0 & 124 \\
\hline highlevel & 2,043 & 0.032 & 0.176 & 0 & 1 \\
\hline socializer & 2,043 & 1.514 & 10.080 & 0 & 1 \\
\hline user_age & 2,043 & 17.980 & 15.400 & 75 \\
\hline
\end{tabular}




$$
\begin{aligned}
& \text { ideas_quantity }_{i}=\beta_{0}+\beta_{1} \text { strength }_{i}+\beta_{2} \text { strength }_{i}+\beta_{3} \text { neighbors_ideas }{ }_{i}+\beta_{4} X_{i}+\varepsilon_{i} \quad(M 1 a) \\
& \text { ideas_quantity }_{i}=\beta_{0}+\beta_{1} \text { ties }_{i}+\beta_{2} \text { strength }_{i}+\beta_{3} \text { neighbors_level }_{i}+\beta_{4} X_{i}+\varepsilon_{i} \quad(M 1 b)
\end{aligned}
$$

Model M2 investigates the impact of the entire network's structural characteristics on user innovation, i.e., the effects of all direct and indirect relations (global effect). The dependent variable is the number of users' ideas for M2a, and the quality of users' ideas for M2b. The main explanatory variables are two structural characteristic variables: centrality (central) and bridge location (bridge). Specifically, we use three indicators (i.e., in-degree centrality, eigenvector centrality, and closeness centrality) to proxy the variable central. $X$ and $\varepsilon_{i}$ refer to the control variables and the error terms.

$$
\begin{gathered}
\text { ideas }_{\text {quantityi }}=\beta_{0}+\beta_{1} \text { central }+\beta_{2} \text { bridge }+\beta_{3} X_{i}+\varepsilon_{i} \quad(M 2 a) \\
\text { ideas_quantity }_{i}=\beta_{0}+\beta_{1} \text { central }+\beta_{2} \text { bridge }+\beta_{3} X_{i}+\varepsilon_{i} \quad(M 2 b)
\end{gathered}
$$

Considering that the dependent variables, both the number of ideas and the quality of ideas (i.e., the number of supporting statements ideas obtained), are nonnegative integers and count variables, Poisson regression and negative binomial regression are widely used (Wooldridge, 2009). These techniques differ from ordinary least squares (OLS) regression in the assumptions of the conditional mean and variance in the dependent variable. Specifically, Poisson regression assumes that the dependent variable's conditional mean should equal its variance, while negative binomial regression models do not have this assumption. Negative binomial regression introduces a new parameter to cope with the overdispersion problem, i.e., the variance is larger than the conditional mean. As shown in Table 3, the mean of the dependent variables in this study is quite different from their variances. Therefore, we adopt negative binomial regression to estimate the empirical models using Stata 14.0 software.

\section{EMPIRICAL RESULTS}

\subsection{The Effects of Relational Characteristics on User Innovation}

Table 4 shows the regression results of the model M1. Regressions (1) and (2) examine the influence of relational characteristics on the number of ideas and the quality of ideas, respectively. Both the results of (1) and (2) show that the coefficients of the number of ties (ties) are positive and significant, while the coefficients of $t_{i e s^{2}}$ are negative and significant. This result confirms the inverted U-shaped relationship between the number of ties and user innovation outcomes (i.e., both the number and quality of user ideas). Thus, H1a and H1b are supported. When the total number of "follow-up" ties one user has is less than the fixed turning point, the marginal effect brought by the ties is positive. The more ties a user has, the more and better ideas he/she would produce. Otherwise, when the total number of "follow-up" ties exceeds the turning point, the marginal effect brought by the ties becomes negative.

At the same time, the strength of the relationships (strength) positively and significantly affects both the number of ideas $(\beta=0.299, \mathrm{p}<0.01)$ and the quality of ideas $(\beta=0.434, \mathrm{p}<0.01)$. Therefore, $\mathrm{H} 2 \mathrm{a}$ and $\mathrm{H} 2 \mathrm{~b}$ are supported. The more interactions there are between users, the more likely users are to produce new and excellent ideas. However, neighbors' innovation characteristics show a nonsignificant effect on user innovation outcomes. The number of neighbors' ideas (neighbors_ideas) could not influence the number of focal users' $(\beta=-0.001, \mathrm{p}=0.611)$. Moreover, the innovation level of neighbors (neighbors_level) could not promote the quality of ideas focal users proposed $(\beta=-0.066$, $\mathrm{p}=0.848$ ). Thus, $\mathrm{H} 3 \mathrm{a}$ and $\mathrm{H} 3 \mathrm{~b}$ are not supported. 
Table 4. Results of M1: The Effect of Relational Characteristics on User Innovation

\begin{tabular}{|c|c|c|}
\hline \multirow{2}{*}{ Variable } & Number of ideas & Quality of ideas \\
\hline & (1) & (2) \\
\hline \multirow[t]{2}{*}{ ties } & $0.006 * * *$ & $0.007 * *$ \\
\hline & $(0.001)$ & $(0.003)$ \\
\hline \multirow[t]{2}{*}{ ties $^{2}$} & $-0.000 * * * \oplus$ & $-0.000 * * *$ \\
\hline & $(0.000)$ & $(0.000)$ \\
\hline \multirow[t]{2}{*}{ strength } & $0.299 * * *$ & $0.434 * * *$ \\
\hline & $(0.016)$ & $(0.044)$ \\
\hline \multirow[t]{2}{*}{ neighbors_ideas } & -0.001 & \\
\hline & $(0.002)$ & \\
\hline \multirow[t]{2}{*}{ neighbors_level } & & -0.066 \\
\hline & & $(0.345)$ \\
\hline \multirow[t]{2}{*}{ pastideas } & $0.033 * * *$ & $-0.028 * * *$ \\
\hline & $(0.005)$ & $(0.006)$ \\
\hline \multirow[t]{2}{*}{ highlevel } & $-0.284 * * *$ & $1.083 * * *$ \\
\hline & $(0.088)$ & $(0.248)$ \\
\hline \multirow[t]{2}{*}{ socializer } & $-0.014 * * *$ & 0.003 \\
\hline & $(0.003)$ & $(0.004)$ \\
\hline \multirow[t]{2}{*}{ user_age } & $-0.003 * *$ & $0.021 * * *$ \\
\hline & $(0.001)$ & $(0.004)$ \\
\hline \multirow[t]{2}{*}{ Constant } & $-0.151 * * *$ & $3.618 * * *$ \\
\hline & $(0.044)$ & $(0.149)$ \\
\hline Observations & 2,043 & 2,043 \\
\hline
\end{tabular}

Notes: Robust standard errors are reported in the parentheses. ${ }^{* *} p<.01 ;{ }^{* *} p<.05 ;{ }^{*} p<.1$; NS: not significant. The value at $\square$ and, is -0.00000699 and -0.00000720 separately.

Furthermore, we check the distribution of the number of ties, as shown in Figure 6. The histogram and box plot show that most users have fewer than 200 ties, while several users have more than 400 ties, and even one extreme case has more than 1000 ties. Then, we also plot the log-log distribution diagram and find a long tail at the end, which causes the distribution to deviate from the power-law

\section{Figure 6. Distribution Diagrams of the Number of Relationships}

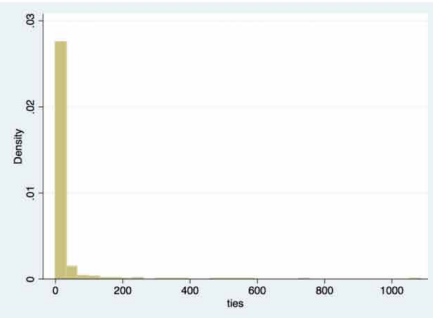

(a) histogram

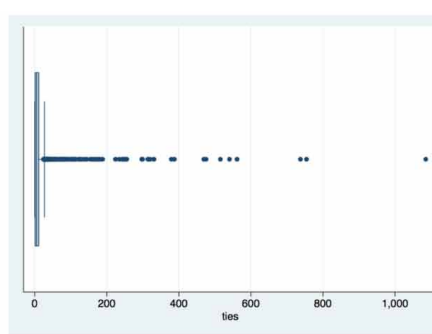

(b) box plot

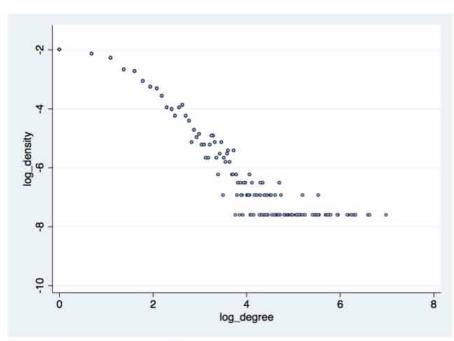

(c)log-log distribution diagram 
Table 5. Results of M1: The Effect of Relational Characteristics on User Innovation (Eliminating Extreme Observations)

\begin{tabular}{|c|c|c|c|c|}
\hline \multirow{2}{*}{ Variable } & \multicolumn{2}{|c|}{ Number of ideas } & \multicolumn{2}{|c|}{ Quality of ideas } \\
\hline & (1) & margins & (2) & margins \\
\hline \multirow[t]{2}{*}{ ties } & $0.012 * * *$ & $0.026 * * *$ & $0.029 * * *$ & $7.682 * * *$ \\
\hline & $(0.002)$ & $(0.004)$ & $(0.006)$ & $(2.509)$ \\
\hline \multirow[t]{2}{*}{ ties $^{2}$} & $-0.000 * * *$ & $-0.000 * * * \oplus$ & $-0.000 * * *$ & $-0.024 * * *$ \\
\hline & $(0.000)$ & $(0.000)$ & $(0.000)$ & $(0.007)$ \\
\hline \multirow[t]{2}{*}{ strength } & $0.277 * * *$ & $0.577 * * *$ & $0.336 * * *$ & $87.910 * * *$ \\
\hline & $(0.015)$ & $(0.042)$ & $(0.047)$ & (17.176) \\
\hline \multirow[t]{2}{*}{ neighbors_ideas } & -0.004 & -0.007 & & \\
\hline & $(0.002)$ & $(0.005)$ & & \\
\hline \multirow[t]{2}{*}{ neighbors_level } & & & -0.198 & -51.888 \\
\hline & & & $(0.318)$ & (85.029) \\
\hline \multirow[t]{2}{*}{ pastideas } & $0.030 * * *$ & $0.062 * * *$ & $-0.035 * * *$ & $-9.163 * * *$ \\
\hline & $(0.005)$ & $(0.010)$ & $(0.007)$ & (2.318) \\
\hline \multirow[t]{2}{*}{ highlevel } & $-0.323^{* * *}$ & $-0.674 * * *$ & $0.988^{* * *}$ & $258.404 * * *$ \\
\hline & $(0.089)$ & (0.194) & $(0.273)$ & $(78.761)$ \\
\hline \multirow[t]{2}{*}{ socializer } & $-0.014 * * *$ & $-0.028 * * *$ & 0.003 & 0.665 \\
\hline & $(0.003)$ & $(0.006)$ & $(0.004)$ & $(1.102)$ \\
\hline \multirow[t]{2}{*}{ user_age } & $-0.003 * * *$ & $-0.007 * *$ & $0.021 * * *$ & $5.547 * * *$ \\
\hline & $(0.001)$ & $(0.003)$ & $(0.004)$ & (1.079) \\
\hline \multirow[t]{2}{*}{ Constant } & $-0.134 * * *$ & & $3.638 * * *$ & \\
\hline & $(0.042)$ & & $(0.142)$ & \\
\hline Observations & 2,035 & & 2,035 & \\
\hline
\end{tabular}

Notes: Robust standard errors are reported in the parentheses. ${ }^{* * *} p<.01 ;{ }^{* *} p<.05 ;{ }^{*} p<.1$; NS: not significant. The value at $\square$ is -0.000075 .

distribution. In large networks, the node connectivity follows a scale-free power-law distribution (Barabási \& Albert, 1999; Li et al., 2015). Based on all these distribution checks, we infer that there are several extreme users with a large number of abnormal ties, which should be eliminated from the sample.

Therefore, this study eliminates extreme observations (a total of 8 users) with more than 400 ties and regresses the remaining observations, as shown in Table 5. The results in Table 5 are consistent with those in Table 4. The number of ties (ties) shows a quadric relationship with both the number and quality of user ideas. The strength of ties is significantly and positively related to both the number and quality of user ideas, while the neighbors' characteristics are nonsignificant.

Given the margins in Table 5, we can draw the relationship chart for the number of ties and user innovation (i.e., the number of ideas and the quality of ideas), as shown in Figure 7. Figure 7 shows the curvilinear relationships, with turning points at approximately 170 for chart (a) and 160 for chart (b). This demonstrates that the number of ties that users on the LEGO Ideas platform can control has a certain threshold (approximately 160 to 170). If the number of ties one user maintains exceeds that threshold, the increase in relationships will instead reduce the benefits to user innovation. 
Figure 7. Inverted U-shaped Relationship Between the Number of Ties and User Innovation

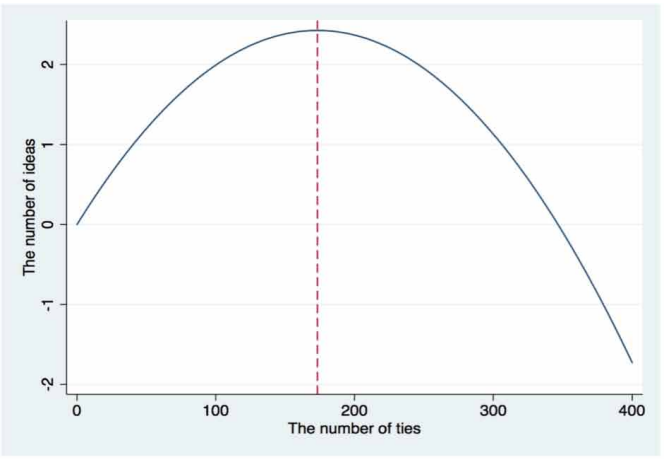

(a) ties and the number of ideas

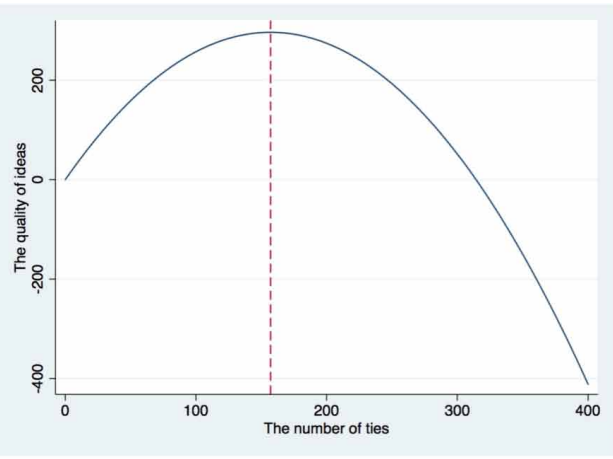

(b) ties and the quality of ideas

\subsection{The Effects of Structural Characteristics on User Innovation}

Table 6 shows the regression results of model M2, in which the variable centrality is measured by standardized in-degree centrality. Regressions (1) and (2) examine the effects of structural characteristics of user social networks on the number of users' ideas and these ideas' quality, respectively. Centrality is positively related to both the number of ideas $(\beta=51.291, \mathrm{p}<0.01)$ and the quality of ideas $(\beta=76.185, p<0.01)$. The closer the user is to the network center, the more and better innovative ideas the user will produce. Thus, we can confirm H4a and H4b. Similarly, bridge location

Table 6. Results of M2: The Effects of Structural Characteristics on User Innovation

\begin{tabular}{|l|l|l|}
\hline & Number of ideas & Quality of ideas \\
\hline Variable & $\mathbf{( 1 )}$ & $\mathbf{( 2 )}$ \\
\hline central_indegree & $51.291^{* * *}$ & $76.185 * * *$ \\
\hline & $(7.010)$ & $(15.513)$ \\
\hline bridge & $0.611^{* * *}$ & $1.467 * * *$ \\
\hline & $(0.067)$ & $(0.160)$ \\
\hline pastideas & $0.033^{* * *}$ & $-0.029 * * *$ \\
\hline & $(0.006)$ & $(0.007)$ \\
\hline highlevel & $-0.462 * * *$ & $0.765 * * *$ \\
\hline & $(0.121)$ & $(0.262)$ \\
\hline socializer & $-0.019 * * *$ & -0.004 \\
\hline & $(0.004)$ & $(0.004)$ \\
\hline user_age & $-0.006 * * *$ & $0.018 * * *$ \\
\hline & $(0.002)$ & $(0.003)$ \\
\hline Constant & $0.080^{*}$ & $2.917 * * *$ \\
\hline & $(0.043)$ & $(0.213)$ \\
\hline Observations & 2,043 & 2,043 \\
\hline
\end{tabular}

Notes: Robust standard errors are reported in the parentheses. ${ }^{* * *} p<.01 ;{ }^{* *} p<.05 ;{ }^{*} p<.1$; NS: not significant. 
Table 7. Results of M2: The Effects of Structural Characteristics on User Innovation (Alter Indicators for Centrality)

\begin{tabular}{|c|c|c|c|c|}
\hline \multirow{2}{*}{ Variable } & \multicolumn{2}{|c|}{ Number of ideas } & \multicolumn{2}{|c|}{ Quality of ideas } \\
\hline & (1) & (2) & (3) & (4) \\
\hline \multirow[t]{2}{*}{ central_eigenvector } & $16.452 * * *$ & & $17.040 * * *$ & \\
\hline & $(2.164)$ & & $(4.331)$ & \\
\hline \multirow[t]{2}{*}{ central_close } & & $4.785 * * *$ & & -0.499 \\
\hline & & (1.074) & & $(2.149)$ \\
\hline \multirow[t]{2}{*}{ bridge } & $0.596 * * *$ & $0.881 * * *$ & $1.660 * * *$ & $2.122 * * *$ \\
\hline & $(0.070)$ & $(0.077)$ & $(0.157)$ & $(0.197)$ \\
\hline \multirow[t]{2}{*}{ pastideas } & $0.032 * * *$ & $0.034 * * *$ & $-0.029 * * *$ & $-0.031 * * *$ \\
\hline & $(0.006)$ & $(0.007)$ & $(0.006)$ & $(0.007)$ \\
\hline \multirow[t]{2}{*}{ highlevel } & $-0.320 * * *$ & $-0.223^{*}$ & $0.914 * * *$ & $1.089 * * *$ \\
\hline & $(0.109)$ & $(0.121)$ & $(0.244)$ & $(0.216)$ \\
\hline \multirow[t]{2}{*}{ socializer } & $-0.016 * * *$ & $-0.007 *$ & 0.001 & $0.009^{*}$ \\
\hline & $(0.003)$ & $(0.004)$ & $(0.004)$ & $(0.005)$ \\
\hline \multirow[t]{2}{*}{ user_age } & $-0.006 * * *$ & $-0.005^{* * *}$ & $0.019 * * *$ & $0.019 * * *$ \\
\hline & $(0.002)$ & $(0.002)$ & $(0.003)$ & $(0.004)$ \\
\hline \multirow[t]{2}{*}{ Constant } & $0.128 * *$ & $-0.292 * * *$ & $3.391 * * *$ & $3.366 * * *$ \\
\hline & $(0.035)$ & $(0.089)$ & $(0.100)$ & $(0.153)$ \\
\hline Observations & 2,043 & 2,043 & 2,043 & 2,043 \\
\hline
\end{tabular}

Notes: Robust standard errors are reported in the parentheses. ${ }^{* * *} p<.01 ;{ }^{* *} p<.05 ;{ }^{*} p<.1 ;$ NS: not significant.

positively and significantly affects both the number of ideas $(\beta=0.611, p<0.01)$ and the quality of ideas $(\beta=1.467, \mathrm{p}<0.01)$. Thus, $\mathrm{H} 5 \mathrm{a}$ and $\mathrm{H} 5 \mathrm{~b}$ are supported.

Furthermore, we proxy the variable centrality with eigenvector centrality (central_eigenvector) and closeness centrality (central_close), and examine their effects on user innovation. Table 7 shows the results. Both eigenvector centrality and closeness centrality are significantly and positively related to the number of ideas. However, only eigenvector centrality significantly positively affects the quality of ideas, while closeness centrality has no significant effect. This finding illustrates that closeness centrality is more conducive to improving the number of users' ideas than quality. Table 8 summarizes the results of our hypotheses testing from both this subsection and the previous subsection.

\section{DISCUSSION}

\subsection{Findings}

To explore how online users' interactive relations influence users' innovation outcomes from a holistic perspective, this paper crawls the public data of users' interactions on the LEGO Ideas platform and builds a user social network. Using the social network analysis method and regression, this paper quantifies the online user social network's relational characteristics and structural characteristics and then explores their effects on user innovation. The main findings are as follows.

(1) There is an inverted $\mathbf{U}$-shaped relationship between the number of online ties and user innovation. Through online interactions, the social ties between users are developed. The 
Table 8. Summary of Hypothesis Testing

\begin{tabular}{|l|l|}
\hline Hypothesis & Supported \\
\hline The effects of relational characteristics on user innovation & Yes \\
\hline $\begin{array}{l}\text { H1a. The number of ties that users maintain has a quadratic (inverted U-shaped) relationship with the } \\
\text { number of users' ideas. }\end{array}$ & Yes \\
\hline $\begin{array}{l}\text { H1b. The number of ties that users maintain has a quadratic (inverted U-shaped) relationship with the } \\
\text { quality of users' ideas. }\end{array}$ & Yes \\
\hline H2a. The strength of ties is positively related to the number of users' ideas. & Yes \\
\hline H2b. The strength of ties is positively related to the quality of users' ideas. & No \\
\hline $\begin{array}{l}\text { H3a. The number of ideas online neighbors proposed is positively related to the number of focal users' } \\
\text { ideas. }\end{array}$ & No \\
\hline H3b. The innovation level of neighbors is positively related to the quality of focal users' ideas. & Yes \\
\hline The effects of structural characteristics on user innovation & Yes \\
\hline H4a. Centrality in the network is positively related to the number of users' ideas. & Yes \\
\hline H4b. Centrality in the network is positively related to the quality of users' ideas. & $\begin{array}{l}\text { H5a. The bridge location, i.e., access to structural holes, is positively related to the number of users' } \\
\text { ideas. }\end{array}$ \\
\hline $\begin{array}{l}\text { H5b. The bridge location, i.e., access to structural holes, is positively related to the quality of users' } \\
\text { ideas. }\end{array}$ & Yes \\
\hline
\end{tabular}

empirical results show that when the number of ties built by one user is under a certain threshold (i.e., 160-170 for the LEGO Ideas platform), the more online ties there are, the more useful information and knowledge the user can access and the better the user's innovation outcomes. When the number of ties exceeds the threshold, more online ties will instead decrease user innovation. When a user maintains excessive ties beyond his control, the high cost of relationship maintenance will exceed the ties' benefits.

(2) The strength of ties can improve user innovation. The results demonstrate that the more frequent users' interactions are, the better users' innovation outcomes will be. Generally, users on innovation platforms live almost all over the world and thus have a large amount of heterogeneous innovation knowledge. Their frequent interactions should enhance the knowledge exchange between users, especially regarding the exchange of complex information and the transmission of tacit innovation knowledge.

(3) Neighbors' innovation characteristics have no significant influence on user innovation. Considering the social influence among online users (Centola, 2010; Karsai et al., 2014), we expect that the focal users' innovation could be influenced by their neighbors' characteristics. However, empirical results do not match our expectations. When controlling certain online ties (i.e., the number of ties and tie strength), the social influence from neighbors' characteristics (i.e., the number of neighbors' ideas and the neighbors' innovation level) plays a subtle role in increasing the focal users' ideas or improving the ideas' quality. We believe that one possible reason lies in the difficulty and complexity of innovation behavior. Compared with the simple adoption behavior in previous studies, e.g., registering for an online forum or not, the generation of a new idea or a better idea is a more complex task (Campbell, 1988). Though users exhibit willingness to innovate, it is still difficult for them to produce more and better innovation outcomes when the knowledge and information that derive benefit from online ties have been fixed. Another possible reason lies in the difficulty of absorbing the knowledge from the high-level innovators only by online interactions. 
(4) Centrality has a positive effect on user innovation. Because of greater attention from others, the center position in the entire network should help users gain more resources (e.g., useful information/knowledge flow from others) through not only the direct but also the indirect relations. Additionally, because of its high status and good reputation, the center position should empower users with a higher chance to exchange information with others. All of the three centrality indicators (i.e., in-degree centrality, eigenvector centrality, and closeness centrality) in the empirical analysis confirm the significant effect.

(5) The bridge location has a positive effect on user innovation. The bridge location in the online user social network plays the same strategic role as it does in the offline network. Although the Internet has dramatically increased the transparency of information between online users, given the limited rationality of individuals, users are unable to obtain and process all this information. The bridge location of the user social network could benefit the user with a fast way to access high-value information (e.g., nonredundant innovation knowledge) with limited time and effort.

\subsection{Research Implications}

This study advances theoretical knowledge in several aspects. First, it offers complementary insights to previous studies on the effects of users' online interactive relations on user innovation (e.g., Wasko \& Faraj, 2005; Chan et al., 2015). Specifically, we investigate online relations from both the relational embeddedness and structural embeddedness perspectives. Hence, both the local effect (i.e., direct relations) and global effect (i.e., direct and indirect relations) are considered when studying the effects. Using the method of social network analysis, multidimensional properties of social networks are qualified, i.e., the relational characteristics (the number of ties, the strength of ties, and the innovation characteristics of neighbors) qualified by the ego-centered network, and structural characteristics (centrality and bridge location) qualified by the entire work. Furthermore, we investigate user innovation from both the quantity (i.e., the number of ideas) and quality (i.e., the quality of ideas) dimensions. All these efforts provide a full view of how online users' interactive relations influence users' innovation outcomes.

Second, we validate the curvilinear relationship between the number of online ties and user innovation in the research context of the LEGO Ideas platform. Some studies have confirmed the inverted U-shaped relationship between the number of ties and innovation performance in the context of the workplace (e.g., McFadyen \& Cannella Jr., 2004; Zhou et al., 2009). We examine this pattern for the online social network and draw the chart to visualize it. Moreover, the threshold of the number of online ties is qualified. This serves to enlighten future studies on the relationship between online ties and individual performance.

Third, we measure centrality by three network indicators — in-degree centrality, eigenvector centrality, and closeness centrality - overcoming the one-sidedness of using only one indicator. All three indicators show positive effects on user innovation, which provides solid validity for the importance of the central location. Additionally, there is a small difference between these three indicators. The in-degree and eigenvector centrality can help improve the quantity and quality of innovation outcomes, while closeness centrality is more conducive to improving the number of users' ideas rather than their quality.

Fourth, for user innovation, the online social network benefits the individuals more by the information flow and social learning, rather than social influence. Different from the simple adoption behavior, which is diffused in the network largely by social influence, the innovation behavior is one complex task. In addition, with only the willingness to innovate driven by the social influence of neighbors, users could not help improving their innovation outcomes. More importantly, the generation of a novel idea requires users to access and absorb diverse knowledge and information, which is embedded in the online social network. Furthermore, online interactions play an essential role in inspiring users with new ideas through learning from others. 


\subsection{Practical Implications}

This paper proposes some implications that may allow online users to improve their innovation outcomes. Based on the proverb "the more friends, the better", a large number of users tend to maintain a large number of online relationships. However, this study illustrates that excessive online ties are harmful to user innovation. A decent number of online relations within the users' control is the best choice for users. When users have a large number of online ties, they should shift their focus to increasing their interactions with their connections to deepen their knowledge sharing and exchange. Moreover, users should also pay attention to increasing the diversity of their online ties and taking strategic bridge positions in the network, which would benefit them with access to heterogeneous knowledge.

This paper also offers some managerial implications for the innovation platform, i.e., identifying and managing the core users based on social network analysis. This study reveals that users who have a certain number of ties with high tie strength, as well as users in the center or the bridge locations of the network, can produce better ideas. These users are the core innovators on the platform. Platforms can provide special incentives and management for such users to enhance their platform identification and involvement and motivate them to continuously propose new ideas. Specific management tactics for core users can allow the platform to allocate limited firm resources to critical users, which helps improve the platform innovation performance at a low cost.

\subsection{Limitations and Future Research Directions}

This paper has, of course, its limitations. First, and most significant, is that our analysis covers only one online innovation platform, LEGO Ideas. Though the successful operation of LEGO Ideas makes it a good starting point to study online user innovation, this is only a starting point. It is important to test the findings in additional contextualized online innovation platforms that would thus become candidates for a set of general principles of online user innovation. Second, we investigate only the user relationships as one-way "follow-up" ties and their effects on user innovation. However, Rishika and Ramaprasad (2019) have examined the effects of both one-way ties and reciprocated ties and find that reciprocated ties exert a greater influence on users' contribution behavior than one-way ties, while tie strength amplifies the effect. The reciprocated ties, as well as the interactive effects of ties' number and strength, need to be investigated in future work. Furthermore, the user social network in this paper is static. It cannot capture the dynamic effects of a user social network on user innovation. Future researchers might explore these dynamic effects by collecting panel data and using dynamic network analysis technology.

\section{CONCLUSION}

Combining social network analysis and regression methods, this paper holistically examines the effects of online user social networks on user innovation. In the context of an online innovation platform, we built the social network using the users' interaction data and then qualify the network relational characteristics (i.e., the number of ties, the strength of ties, and neighbors' characteristics) by the ego-centered network and the network structural characteristics (i.e., centrality and bridge location) by the entire network. Through a set of regressions and robustness checks, the multidimensional network effects are conducted. The number of ties has a quadratic relationship with user innovation outcomes. The strength of ties can improve user innovation, while the neighbors' characteristics cannot. Furthermore, both the centrality and bridge location in the online social network can benefit users to generate more and better ideas. These findings have certain implications for both the theoretical purview and user innovation practice. This study is a step forward in answering the question of how to improve innovations outcomes of online users from the social network perspective. 


\section{ACKNOWLEDGMENT}

This research was supported by the National Natural Science Foundation of China [grant number 72072103]; the Shandong Provincial Natural Science Foundation of China [grant number ZR2019BG004]. 


\section{REFERENCES}

Akcigit, U., Caicedo, S., Miguelez, E., Stantcheva, S., \& Sterzi, V. (2018). Dancing with the stars: Innovation through interactions. National Bureau of Economic Research Working Paper Series, No. 24466. 10.3386/w24466

Arnaboldi, V., Conti, M., Passarella, A., \& Dunbar, R. I. M. (2017). Online social networks and information diffusion: The role of ego networks. Online Social Networks and Media, 1, 44-55. doi:10.1016/j.osnem.2017.04.001

Bapna, R., Gupta, A., Rice, S., \& Sundararajan, A. (2017). Trust and the strength of ties in online social networks: An exploratory field experiment. Management Information Systems Quarterly, 41(1), 115-130. doi:10.25300/ MISQ/2017/41.1.06

Barabási, A.-L., \& Albert, R. (1999). Emergence of scaling in random networks. Science, 286(5439), 509-512. doi:10.1126/science.286.5439.509 PMID:10521342

Bonacich, P. (1987). Power and centrality: A family of measures. American Journal of Sociology, 92(5), 1170-1182. doi:10.1086/228631

Bott, E. (1957). Family and social network. Tavistock.

Burt, R. S. (1992). Structural holes: The social structure of competition. Harvard University Press. doi:10.4159/9780674029095

Burt, R. S. (2004). Structural holes and good ideas. American Journal of Sociology, 110(2), 349-399. doi: $10.1086 / 421787$

Campbell, D. J. (1988). Task complexity: A review and analysis. Academy of Management Review, 13(1), 40-52. doi:10.5465/amr.1988.4306775

Centola, D. (2010). The spread of behavior in an online social network experiment. Science, 329(5996), 1194-1197. doi:10.1126/science.1185231 PMID:20813952

Černe, M., Nerstad, C. G. L., Dysvik, A., \& Škerlavaj, M. (2014). What goes around comes around: Knowledge hiding, perceived motivational climate, and creativity. Social Science Electronic Publishing, 57(1), 172-192. doi:10.5465/amj.2012.0122

Chan, K. W., Li, S. Y., \& Zhu, J. J. (2015). Fostering customer ideation in crowdsourcing community: The role of peer-to-peer and peer-to-firm interactions. Journal of Interactive Marketing, 31, 42-62. doi:10.1016/j. intmar.2015.05.003

Chiu, C.-M., Hsu, M.-H., \& Wang, E. T. G. (2006). Understanding knowledge sharing in virtual communities: An integration of social capital and social cognitive theories. Decision Support Systems, 42(3), 1872-1888. doi:10.1016/j.dss.2006.04.001

Cialdini, R. B., \& Goldstein, N. J. (2004). Social influence: Compliance and conformity. Annual Review of Psychology, 55(1), 591-621. doi:10.1146/annurev.psych.55.090902.142015 PMID:14744228

Coleman, J. S. (1988). Social capital in the creation of human capital. American Journal of Sociology, 94, 95-120. doi:10.1086/228943

Di Gangi, P. M., \& Wasko, M. (2009). Steal my idea! Organizational adoption of user innovations from a user innovation community: A case study of Dell Ideastorm. Decision Support Systems, 48(1), 303-312. doi:10.1016/j. dss.2009.04.004

Dunbar, R. I., Arnaboldi, V., Conti, M., \& Passarella, A. (2015). The structure of online social networks mirrors those in the offline world. Social Networks, 43, 39-47. doi:10.1016/j.socnet.2015.04.005

Ellison, N. B., Vitak, J., Gray, R., \& Lampe, C. (2014). Cultivating social resources on social network sites: Facebook relationship maintenance behaviors and their role in social capital processes. Journal of ComputerMediated Communication, 19(4), 855-870. doi:10.1111/jcc4.12078

Freeman, L. C. (1978). Centrality in social networks conceptual clarification. Social Networks, 1(3), 215-239. doi:10.1016/0378-8733(78)90021-7 
Goes, P. B., Lin, M., \& Au Yeung, C. (2014). "Popularity effect" in user-generated content: Evidence from online product reviews. Information Systems Research, 25(2), 222-238. doi:10.1287/isre.2013.0512

Goyal, S. (2012). Connections: An introduction to the economics of networks. Princeton University Press.

Granovetter, M. (1985). Economic action and social structure: The problem of embeddedness. American Journal of Sociology, 91(3), 481-510. doi:10.1086/228311

Granovetter, M. (1992). Problems of explanation in economic sociology. In N. Nohria \& R. Eccles (Eds.), Networks and organizations: Structure, form and action (pp. 25-56). Harvard Business School Press.

Granovetter, M. S. (1973). The strength of weak ties. American Journal of Sociology, 78(6), 1360-1380. doi: $10.1086 / 225469$

Grewal, R., Lilien, G. L., \& Mallapragada, G. (2006). Location, location, location: How network embeddedness affects project success in open source systems. Management Science, 52(7), 1043-1056. doi:10.1287/ mnsc. 1060.0550

Guo, W., Liang, R. Y., Wang, L., \& Peng, W. (2017). Exploring sustained participation in firm-hosted communities in china: The effects of social capital and active degree. Behaviour \& Information Technology, 36(3), 223-242. doi:10.1080/0144929X.2016.1212402

Huffaker, D. (2010). Dimensions of leadership and social influence in online communities. Human Communication Research, 36(4), 593-617. doi:10.1111/j.1468-2958.2010.01390.x

Hwang, E. H., Singh, P. V., \& Argote, L. (2019). Jack of all, master of some: Information network and innovation in crowdsourcing communities. Information Systems Research, 30(2), 389-410. doi:10.1287/isre.2018.0804

Jabr, W., Mookerjee, R., Tan, Y., \& Mookerjee, V. (2014). Leveraging philanthropic behavior for customer support: The case of user support forums. Management Information Systems Quarterly, 38(1), 187-208. doi:10.25300/ MISQ/2014/38.1.09

Kane, G. C., Alavi, M., Labianca, G., \& Borgatti, S. P. (2014). What's different about social media networks? A framework and research agenda. Management Information Systems Quarterly, 38(1), 275-304. doi:10.25300/ MISQ/2014/38.1.13

Karsai, M., Iiguez, G., Kaski, K., \& Kertész, J. (2014). Complex contagion process in spreading of online innovation. Journal of the Royal Society, Interface, 11(101), 20140694. Advance online publication. doi:10.1098/ rsif.2014.0694 PMID:25339685

Kohn, N. W., Paulus, P. B., \& Choi, Y. H. (2011). Building on the ideas of others: An examination of the idea combination process. Journal of Experimental Social Psychology, 47(3), 554-561. doi:10.1016/j.jesp.2011.01.004

Levin, D. Z., \& Cross, R. (2004). The strength of weak ties you can trust: The mediating role of trust in effective knowledge transfer. Management Science, 50(11), 1477-1490. doi:10.1287/mnsc.1030.0136

Li, M., Kankanhalli, A., \& Kim, S. H. (2016). Which ideas are more likely to be implemented in online user innovation communities? An empirical analysis. Decision Support Systems, 84, 28-40. doi:10.1016/j. dss.2016.01.004

Li, Y., Qian, M., Jin, D., Hui, P., \& Vasilakos, A. V. (2015). Revealing the efficiency of information diffusion in online social networks of microblog. Information Sciences, 293, 383-389. doi:10.1016/j.ins.2014.09.019

Liang, Y., Zhou, R., Chen, J., \& Wei, K. (2016). The impact of power boundary management on the design of company-initiated open innovation platform. Paper presented at the PACIS, Taiwai. https://aisel.aisnet.org/ pacis2016/101

Lin, N. (2002). Social capital: A theory of social structure and action. Cambridge University Press.

Lin, Z., Yang, H., \& Arya, B. (2009). Alliance partners and firm performance: Resource complementarity and status association. Strategic Management Journal, 30(9), 921-940. doi:10.1002/smj.773

McFadyen, M. A., \& Cannella, A. A. Jr. (2004). Social capital and knowledge creation: Diminishing returns of the number and strength of exchange relationships. Academy of Management Journal, 47(5), 735-746. doi: $10.5465 / 20159615$ 
Mention, A.-L., Barlatier, P.-J., \& Josserand, E. (2019). Using social media to leverage and develop dynamic capabilities for innovation. Technological Forecasting and Social Change, 144, 242-250. doi:10.1016/j. techfore.2019.03.003

Muller, E., \& Peres, R. (2019). The effect of social networks structure on innovation performance: A review and directions for research. International Journal of Research in Marketing, 36(1), 3-19. doi:10.1016/j. ijresmar.2018.05.003

Nahapiet, J., \& Ghoshal, S. (1998). Social capital, intellectual capital, and the organizational advantage. Academy of Management Review, 23(2), 242-266. doi:10.5465/amr.1998.533225

Nonaka, I. (1994). A dynamic theory of organizational knowledge creation. Organization Science, 5(1), 14-37. doi:10.1287/orsc.5.1.14

Palacios-Marqués, D., Merigó, J. M., \& Soto-Acosta, P. (2015). Online social networks as an enabler of innovation in organizations. Management Decision, 53(9), 1906-1920. doi:10.1108/MD-06-2014-0406

Panzarasa, P., Opsahl, T., \& Carley, K. M. (2010). Patterns and dynamics of users' behavior and interaction: Network analysis of an online community. Journal of the Association for Information Science and Technology, 60(5), 911-932. doi:10.1002/asi.21015

Pollock, G., \& Dugatkin, L. A. (1992). Reciprocity and the emergence of reputation. Journal of Theoretical Biology, 159(1), 25-37. doi:10.1016/S0022-5193(05)80765-9

Reagans, R., \& McEvily, B. (2003). Network structure and knowledge transfer: The effects of cohesion and range. Administrative Science Quarterly, 48(2), 240-267. doi:10.2307/3556658

Riedl, C., \& Seidel, V. P. (2018). Learning from mixed signals in online innovation communities. Organization Science, 29(6), 1010-1032. doi:10.1287/orsc.2018.1219

Rishika, R., \& Ramaprasad, J. (2019). The effects of asymmetric social ties, structural embeddedness, and tie strength on online content contribution behavior. Management Science, 65(7), 3398-3422. doi:10.1287/ mnsc.2018.3087

Rogers, E. M. (2003). Diffusion of innovations (5th ed.). Free Press.

Schemmann, B., Herrmann, A. M., Chappin, M. M. H., \& Heimeriks, G. J. (2016). Crowdsourcing ideas: Involving ordinary users in the ideation phase of new product development. Research Policy, 45(6), 1145-1154. doi:10.1016/j.respol.2016.02.003

Scott, J. (2012). Social network analysis (3rd ed.). SAGE Publications.

Stanko, M. A. (2016). Toward a theory of remixing in online innovation communities. Information Systems Research, 27(4), 773-791. doi:10.1287/isre.2016.0650

Stephen, A. T., Zubcsek, P. P., \& Goldenberg, J. (2016). Lower connectivity is better: The effects of network structure on redundancy of ideas and customer innovativeness in interdependent ideation tasks. JMR, Journal of Marketing Research, 53(2), 263-279. doi:10.1509/jmr.13.0127

Toral, S. L., Martínez-Torres, M. R., \& Barrero, F. (2010). Analysis of virtual communities supporting oss projects using social network analysis. Information and Software Technology, 52(3), 296-303. doi:10.1016/j. infsof.2009.10.007

Tsai, W., \& Ghoshal, S. (1998). Social capital and value creation: The role of intrafirm networks. Academy of Management Journal, 41(4), 464-476. doi:10.5465/257085

von Briel, F., \& Recker, J. C. (2017). Lessons from a failed implementation of an online open innovation community in an innovative organization. MIS Quarterly Executive, 16(1), 35-46. https://aisel.aisnet.org/misqe/ vol16/iss $1 / 3$

Wasko, M. L., \& Faraj, S. (2005). Why should I share? Examining social capital and knowledge contribution in electronic networks of practice. Management Information Systems Quarterly, 29(1), 35-57. doi:10.2307/25148667

Wasserman, S., \& Faust, K. (1994). Social network analysis: Methods and applications. Cambridge University Press. doi:10.1017/CBO9780511815478 
Watts, D. J., \& Strogatz, S. H. (1998). Collective dynamics of 'small-world' networks. Nature, 393(6684), 440-442. 10.1038/30918

Wellman, B. (1979). The community question: The intimate networks of East Yorkers. American Journal of Sociology, 84(5), 1201-1231. doi:10.1086/226906

Wooldridge, J. M. (2009). Introductory econometrics: A modern approach (4th ed.). Cengage Learning.

Yang, X., \& Li, G. (2016). Factors influencing the popularity of customer-generated content in a companyhosted online co-creation community: A social capital perspective. Computers in Human Behavior, 64, 760-768. doi:10.1016/j.chb.2016.08.002

Zhou, J., Shin, S. J., Brass, D. J., Choi, J., \& Zhang, Z. (2009). Social networks, personal values, and creativity: Evidence for curvilinear and interaction effects. The Journal of Applied Psychology, 94(6), 1544-1552. doi:10.1037/a0016285 PMID:19916661

\section{ENDNOTE}

1 We randomly generate 1000 simple Erdos-Renyi random networks in the same number of nodes and directed edges with the user social network, and calculate the average clustering coefficient for these random networks, that is 0.0042 .

Jiali Chen is a Lecturer of Information Systems in School of Management Engineering at Shandong Jianzhu University, China. She obtained a Ph.D. from Shandong University. Her research interests include online social network, big data analysis, online user behavior. Her paper has appeared in several journals and conferences of information systems, such as PACIS and CNAIS.

Yikai Liang is a lecturer in School of Management Science and Engineering at Shandong University of Finance and Economics, China. He received his Ph.D. in Management Science and Engineering from Shandong University, China. His research interests include e-Government, cloud computing, IT/IS innovation adoption and open government data. His paper has appeared in several journals and conferences of information systems such as GIQ, PACIS, and CNAIS.

Jiacheng Zhang is a graduate student in School of Management at Shandong University, China. His research field is online user behaviors on open innovation community and social Q\&A community.

Guijie Qi is a professor of Information Systems in School of Management at Shandong University, China. He obtained a Ph.D. from Shandong University. He was a visiting scholar at the Chinese University of Hong Kong. He has a deep research in management information system and system theory, management decision, open innovation-based web platform. His research has been published and presented internationally. 